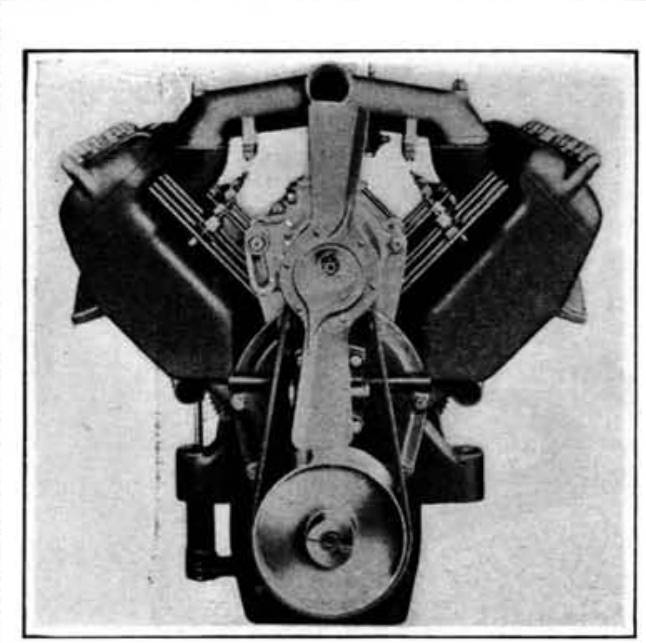

Inclosed overhead valves of the Ferro "Eight," showing exterior push rods operated by a common camshaft.

\section{The How and Why of} the V-Type Motor

Efforts to Produce a Steady Stream of Power by the Use of Eight and Twelve Cylinders

By John S. Harwhite

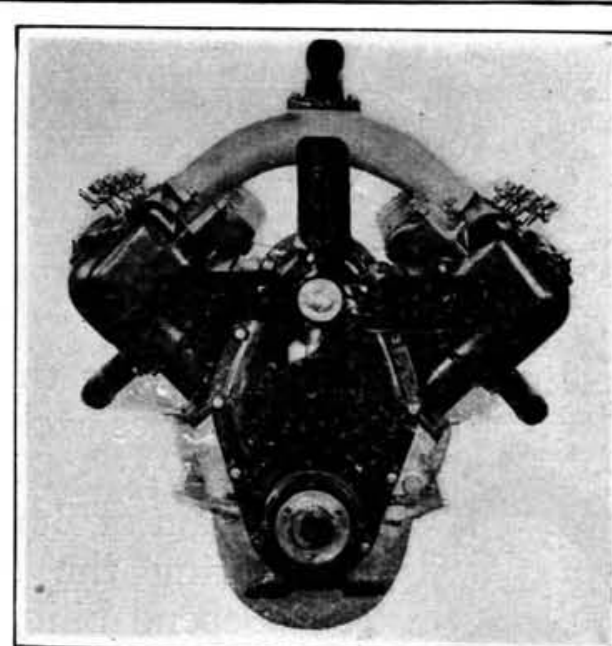

A Buda "Eight," showing the space between the blocs of cylinders reserved between the blocs of cylinders reserved
for the necessary motor attachments.
A Prominent engineer has said that the mere mat$A$ ter of the number of cylinders in an automobile motor is not of primary importance: "The real matter of primary importance is the number of cylinders necessary to produce a car which will perform as its owner wants it to perform." If a single cylinder motor could be designed to give exactly the same results as are obtained from the "Six," there would be no excuse what soever for the production of the "Six." It is only because the manufacturers have believed that certain desirable characteristics of performance, not possessed by a "Four", could be obtained from a "Six" that the large majority of cars selling at over $\$ 1,200$ have been of the six-cylinder rather than the four-cylinder type. If the "Eight" accomplishes these results, there will be no need for the "Twelve;" but if two blocs of sixcylinders each are found to do their work better than the "Eight," the subsequent advent of the twelve-cylinder motor marks another forward stride in moder automobile construction.

As many of the general principles of construction apply both to the V-type "Eight" and the "Twelve," and as the "Wight" was the first of the V-type motors to make its appearance, a description of its leading features will be given first, followed by a discussion of the slight differences to be found between it and the "Twelve,"

The ideal engine produces a steady stream of power This condition is most nearly approached in a gasoline engine by multiplicity of cylinders, and as the automobile engine is of the four-cycle type in which the explosions occur in each cylinder only at alternate revolutions, at least six cylinders are required to obtain an overlapping of power impulses Six cylinders have always been placed in one continuous line. When we always been placed in we reach the eight-cylinder type of design, however, we
find a departure from heretofore accepted practice, for these cylinders are divided into two sections of fou each and are placed with their heads side by side and the lower blocs converging to connect with a common crankshaft. Because of the junction of these two separate motors at the lower point, this type of engine has been termed the "V" eight, although the angle is, as a rule, 90 degrees. It will be seen that this type of construction increases the piston displacement of a motor without adding materially to the length of the crankshaft. Two cylinders are enabled to direct their impulses at each throw of the regular four-cylinder crankshaft, and thus, not only is the power increased, but the frequency of impulses is doubled. Such a motor is no higher than a four-cylinder engine developing approximately one half this power, the only increased dimension being the width, which is easily provided for in cars as at present designed.

Naturally the increase in the number of impulses and the absolute overlapping of the power strokes result in a smoothness of operation that has never been reached in the "Four." In this design each explosion is balanced by compression in other pistons, so that not only is a large proportion of the yibration absorbed, but the angle at which the cylinders are set serves to change the direction of the force of these impulses Consequently, there is no horizontal vibration attendant upon the operation of a well-designed eight-cylinder motor, although it is claimed by six- and twelve-cylinder adherents that these vibrations have been merely changed in direction to those of the horizontal type.

From the manufacturer's standpoint, however, it is probable that one of the principal advantages in the eirht-cylinder motor lies in its simplicity of design and low-production cost. It has been estimated that the cost of manufacture of an eight-cylinder motor of a given power is scarcely as great as that of a six-cylinder machine developing the same energy. There are a fewer number of crankshaft bearings in the former, and it has been shown, in some instances, that the saving in weight is also in favor of the "Right."

There is already a variety of designs of the eightcylinder motor, and it is rather difficult to select the point at which the main classification of the various types should start. In practically all instances, each of the two sets of four cylinders is cast in a single bloc, and these are in turn bolted to a single crankcase. In at least one instance, however; the two series of four cylinders are cast in a single piece, which also comprises the upper half of the crankcase. This is a type of design which naturally makes for great rigidity of construction, although the problems encountered in the foundry may prove serious to some manufacturers. Probably the two great classifications into which eights could be divided are the "opposite" and the "staggered." In the first type each cylinder of one bloc is placed directly opposite the corresponding cylinder in the other bloc. In the second type, one bloc is set a slight distac. In the second type, one bloc is struction in which the cylinders are set directly opposite each other, the connecting rods of each opposing pai must meet at a co a sort of "two-in-one" bearing One method of combining the bearings of the two connecting rods at common point is to fashion the end of one in the form of a yoke, which incloses two sides of the other connecting rod bearing. The yoked, or outer rod, holds the bearing rigid, while the plain, or center rod, oscillates on the outside of the bearing. Another interesting method of obtaining the short and compact design, which is a feature of this type of construction, is to attach the opposite rod to the main rod by knuckle joints similar to a wrist pin. Thus, but one connecting rod is attached directly to each crank, although this bearing takes the thrust and resistance from both cylinders of the pair. This method is resorted to in orde that the crank pin bushings may be made easily removable.

In the case of the staggered "Eight," each connectin rod bearing is separate. Although those of the two pairs of opposite cylinders are placed side by side, each may be tightened or fitted separately, however, and we really have eight "big end" bearings.

In the majority of eight-cylinder designs the valves are placed on the inside so that they may be operated from a single camshaft located at the lower point of the " $v$," just above the crankshaft, and driven by the usual form of two-to-one gear or silent chain. Thi design is easily arranged, inasmuch as the camshaf occupies the point of convergence of the valve stems if the latter were extended to intersect. On some motor a single cam is used for the operation of opposite valves so that only eight cams are required in all. If the

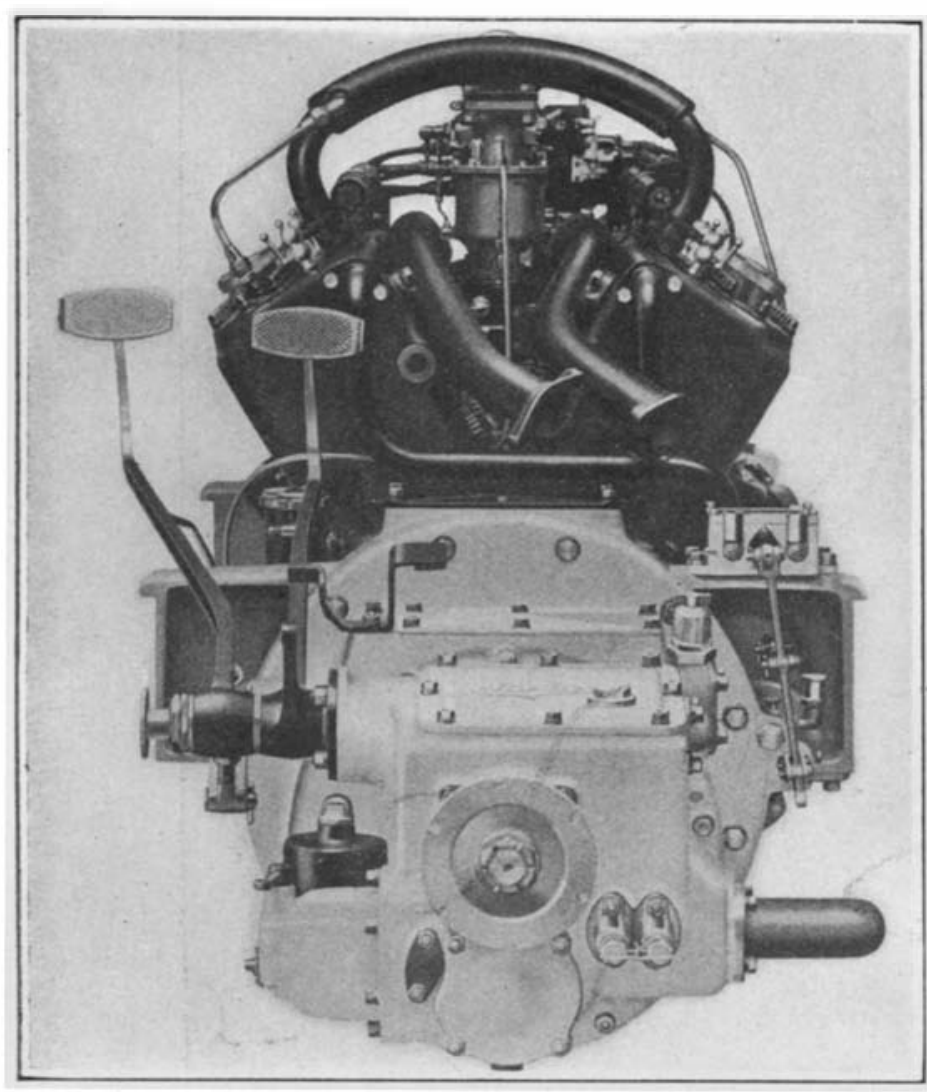

Rear view of the Packard "Twin Six."

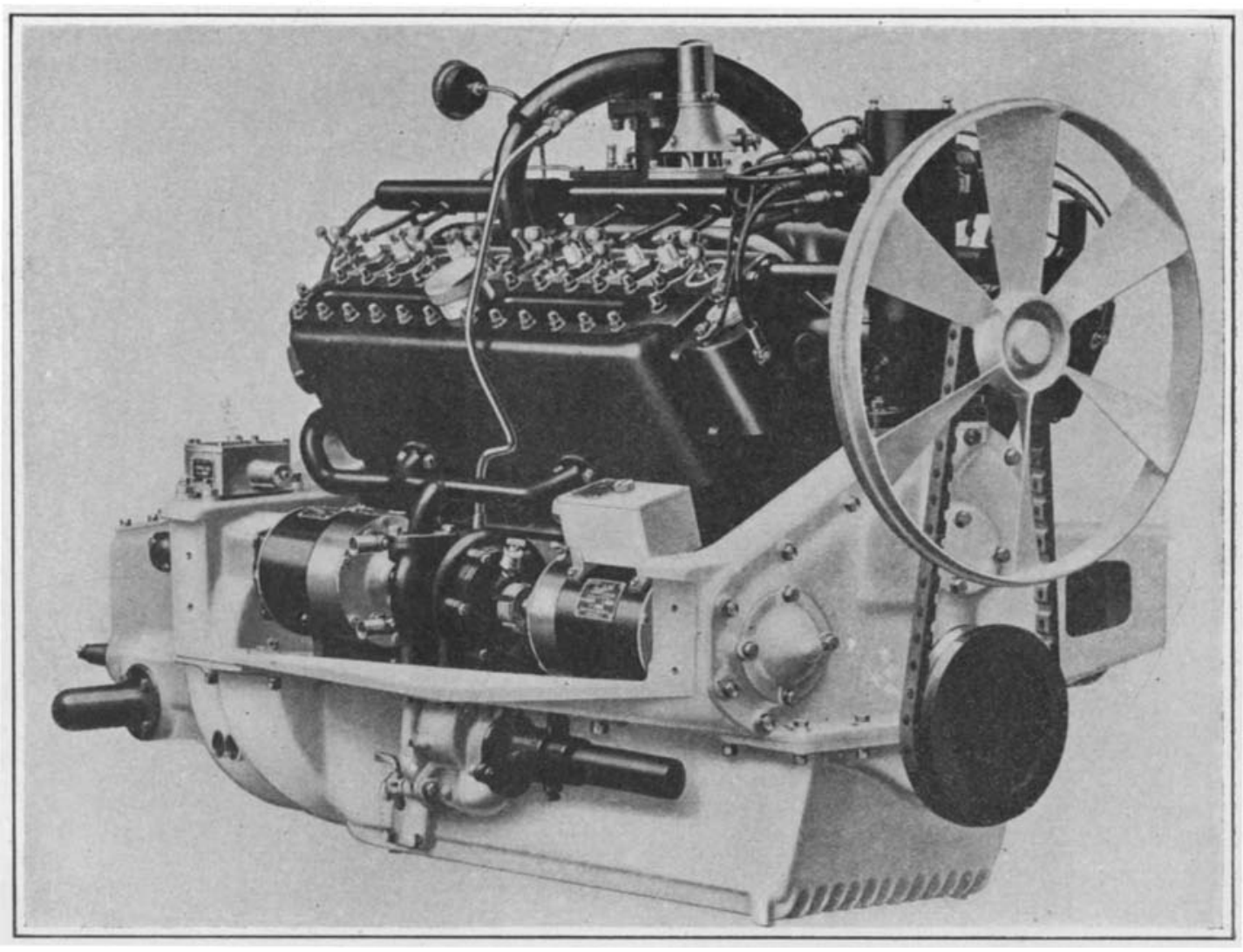

The compact arrangement of the Packard twelve-cylinder motor. 


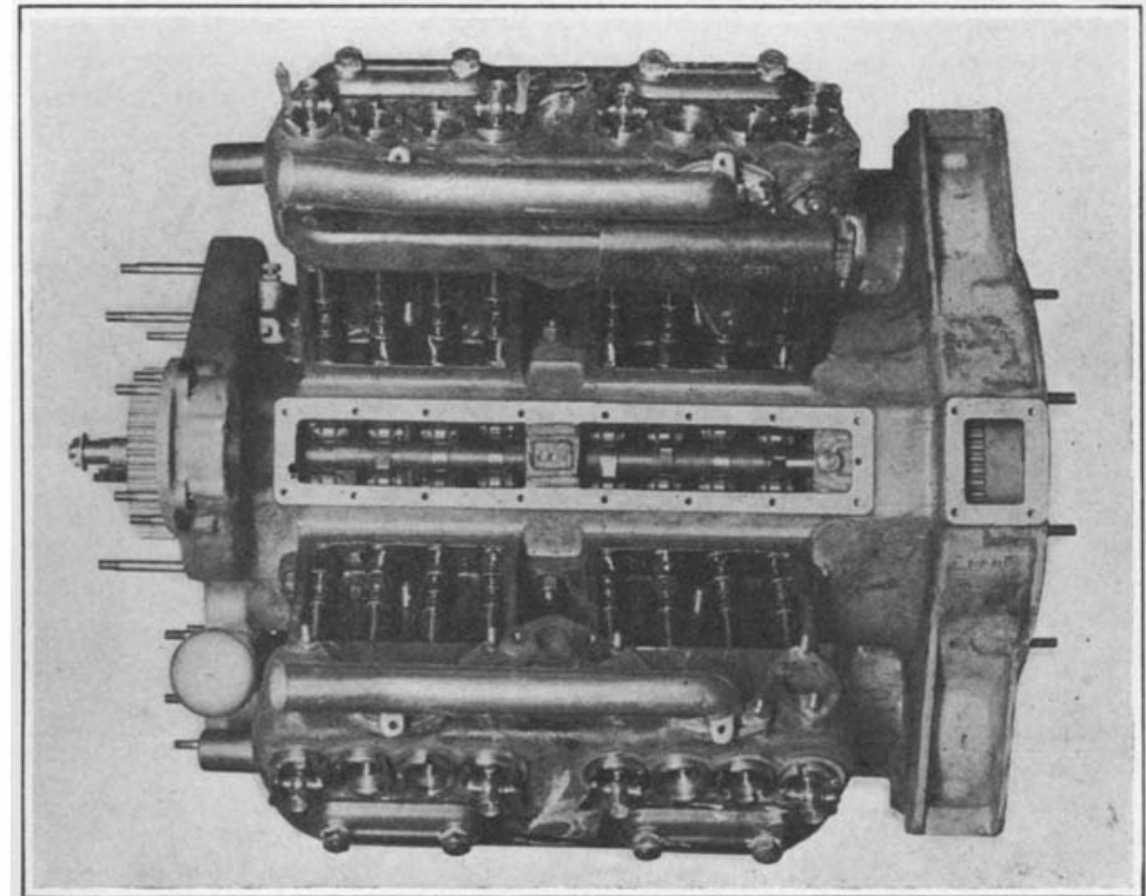

Top view of the King "Eight," showing sixteen valves operated by eight cams on a single camshaft.

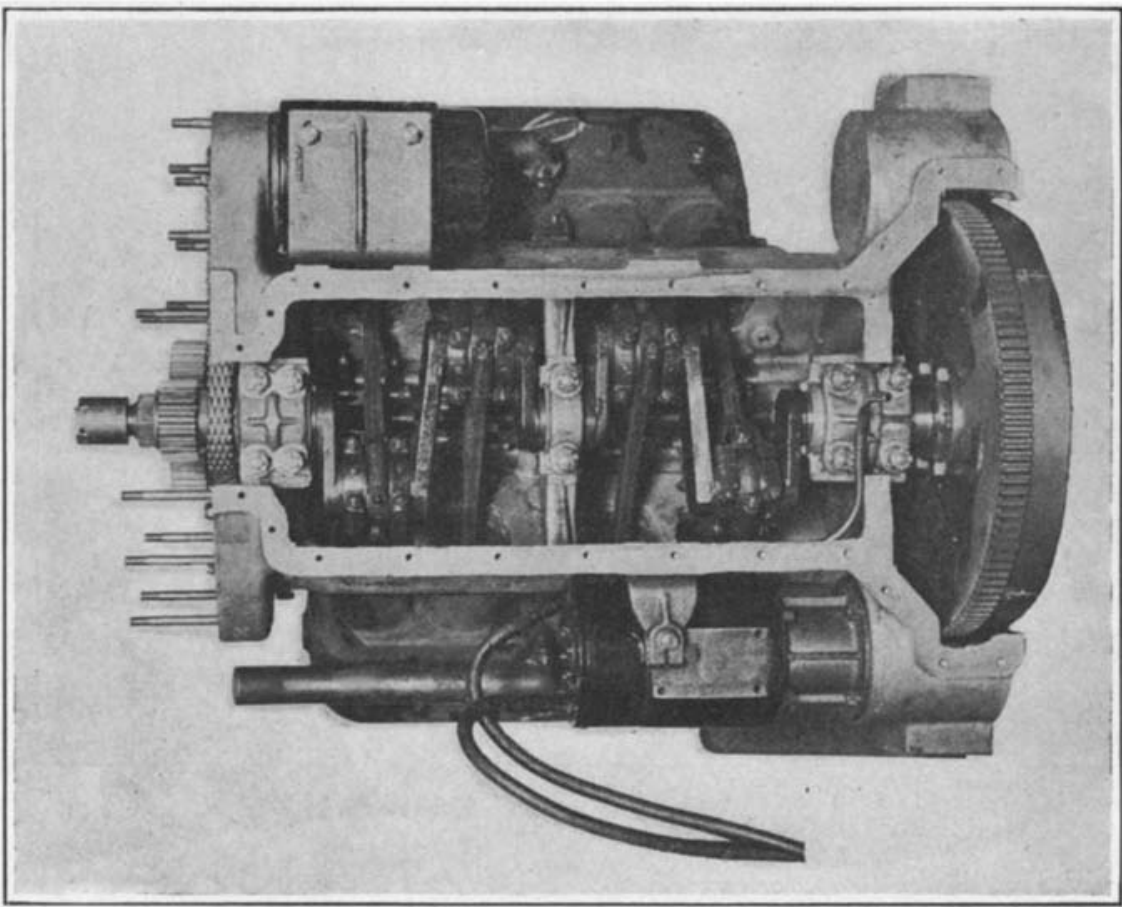

Under view of King, showing yoked connecting rod ends used on many motors in which cylinders are placed opposite one another staggered type of construction is used, however, each is that of the proper lubrication of each of the cylinthough the entire sixteen are, of course, mounted on the same camshaft.

The space in the angle of the $V$ between the blocs of cylinders lends itself well to the accommodation of the various accessories that now form an important part of automobile engine equipment. Because of their location directly over the crankshaft, the starter, generator and timer may be driven without the necessity of introducing an undue number of gears or chains. The concentration of these fixtures results in a compact power plant and renders the accessories themselves easily accessible. There may be an inclination on the part of some, designers, however, to place so many of the accessory outfits in this location that the accessibility of the valve tappets is greatly interfered with. Naturally, the valves of an L-head motor driven by a single camshaft can be reached only from the center of the $\mathrm{V}$. Therefore, rather than relegate some of this necessary motor equipment to inaccessible places on the side or in front of the motor, some designers have proceeded to reverse the bloc castings and thus bring the valves on the outside. This, of course, necessitates the use of two camshafts, but the valve tappets are rendered accessible and all the motor paraphernalia that the "V" will hold may be safely placed between the blocs.

Another type of eight-cylinder design which lends itself especially well to compactness, as well as accessibility, is that in which the valves are placed overhead and are oper-
ated by push rods extending from a single camshaft. Such valves are placed in a removable head on each bloc, which facilitates valve grinding without the necessity of disturbing any of the starting, charging, ignition or carburetion systems that may be placed in the "V."

One of the principal problems with which the designer of the eight-cylinder motor has had to contend ders. The ordinary type of splash feed for the piston and cylinder walls will hardly serve its purpose in this case, for the bloc first encountered in the upward swing of the crank would be the one to receive nearly all the benefit of the lubrication at the expense of the bloc on the opposite side. In motorcycles this difficulty has

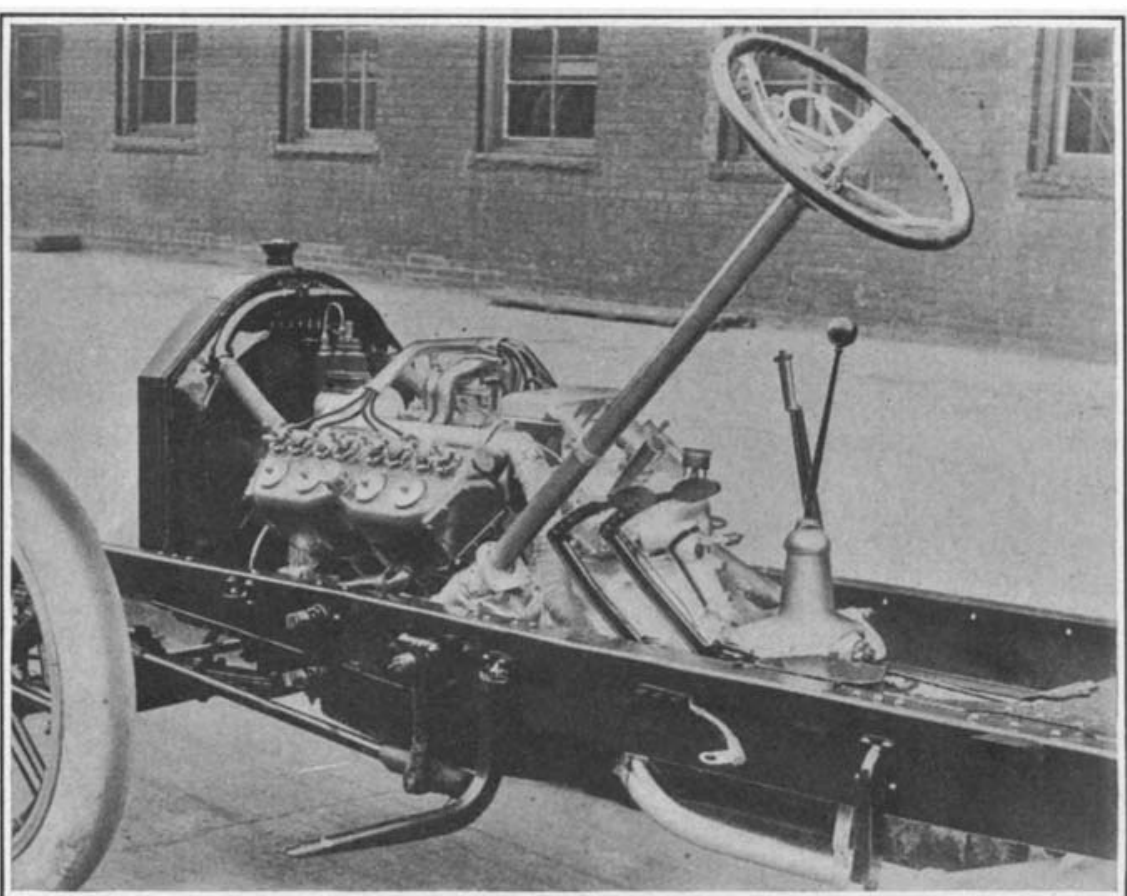

the Cadillac "Eight" lends itself to accommodation in a short bonnet. been overcome, to a certain extent, by placing a baffle plate at the rear cylinder so that an excess of oil will not reach the piston. Such a proceeding would hardly be satisfactory in the case of a highly-refined eightcylinder automobile motor, and consequently a positive system of oil feed to each cylinder must be used. There are various methods by which this end is accomplished, but as the "Eight" is of the small cylinder, high-speed

ype, it is all the more necessary that whatever system is employed should be positive in its action and supply each piston, as well as each bearing, with its share of lubricant.

The advent of the eight-cylinder motor in this country has produced several problems for the accessory manufacturer to consider, and, in fact, it is probable that the automobile industry as a whole will be more or less affected. For example, not only are there a greater number of explosions at each revolution of the eight-cylinder motor than is the case with the "Four" or "Six," but it is designed to operate at a higher speed. With one type of eight-cylinder motor speeds of 3,000 revolutions per minute in practice are not unknown, and this means the formation of 12,000 distinct sparks in sixty seconds. This has resulted in the refinement of ignition apparatus, until now an eightcylinder motor may be fired as accurately as was the case with a "Four" a few years ago.

As the "Eight" uses a standard shape of four-cylinder crankshaft, so does the "Twelve" or "Twin Six" employ the familiar type of six-cylinder crankshaft with its crank set at an angle of $60 \mathrm{de}$ grees. This difference in crank angle, grewever, This affer opposite blocs of cylinders at an angle of 60 degrees, instead of the 90-degree angle usually found in the "Eight." The "Twelve" is thus inherently a narrower motor than is the "Eight," and this feature presents several interesting points in its favor. The sharper angle between the blocs permits the motor accessories to be placed in convenient positions along the outside of either bloc and thus leaves the inner space free from the examination, adjustments and grinding of the valves. Furthermore, the narrower motor permits of the use of a more accesible steering gear and allows the frame to be narrowed so that the radius required for turning is reduced by a (Concluded on page 29.)

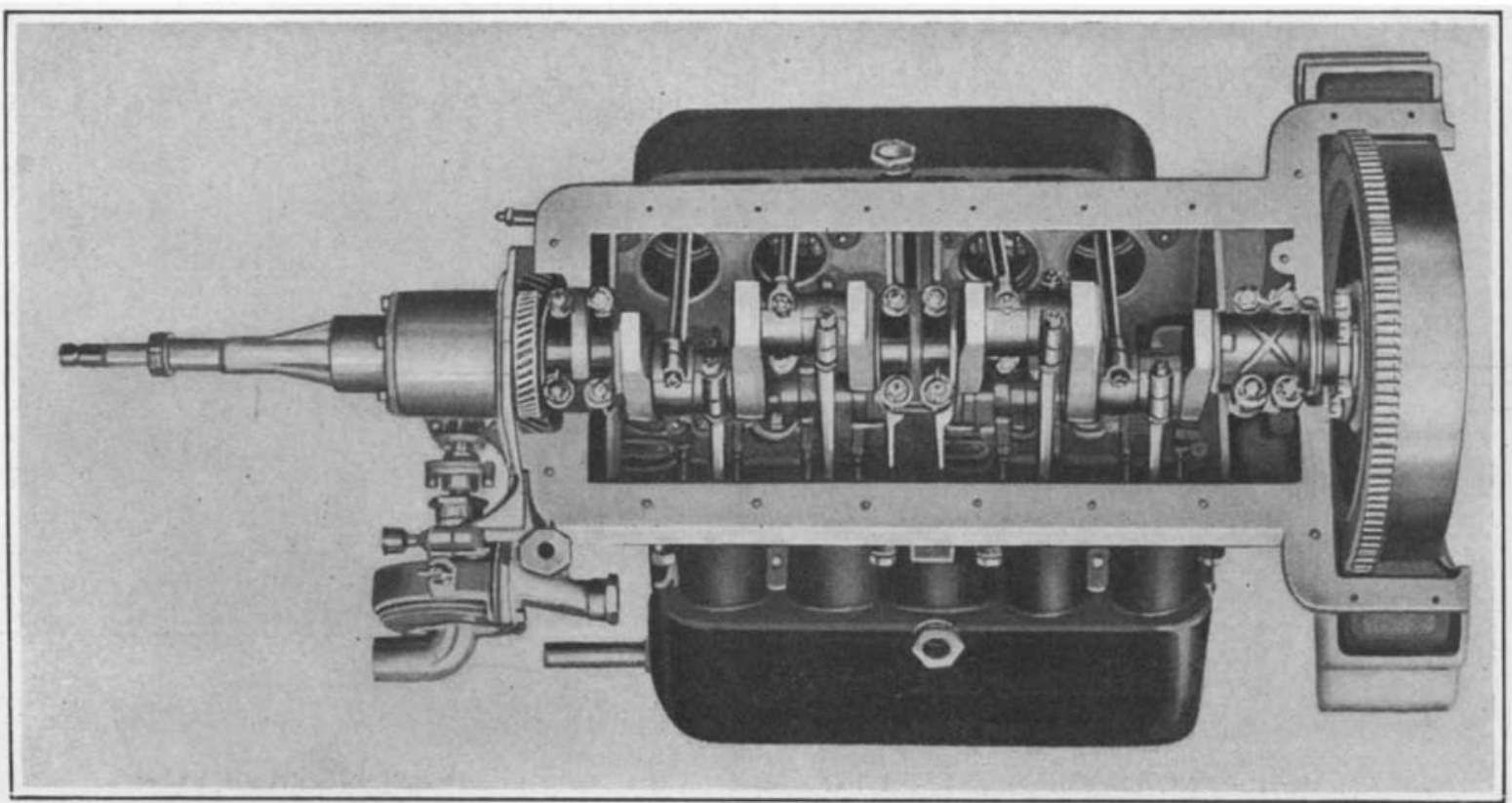

Under view of the Herschel-Spillman motor, showing the staggered arrangement of connecting rods.

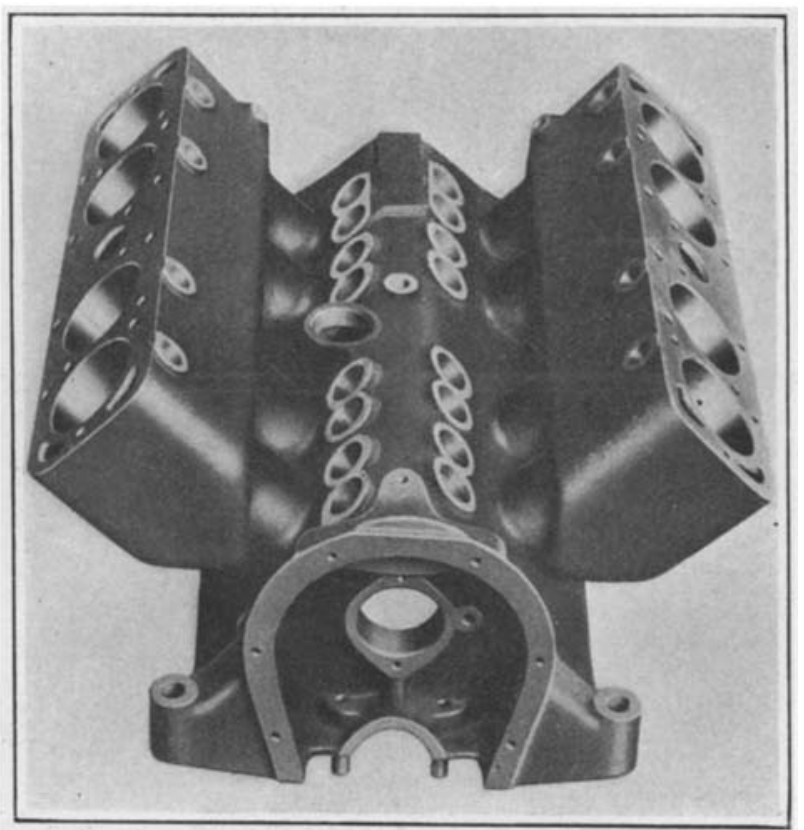

Casting for a Ferro "Eight," including cylinder valves and upper part of crankcase. 
The How and Why of the V-Type it rose from the line of sight and returned Motor

(Concluded from page 21.)

considerable amount. Because for a given power, the cylinders in each bloc of the "Twin Six" are smaller than in a "Single Six," each impulse imparts less strain to the crankshaft. Therefore, the latter may be smaller and, as a rule, a single center bearing will be found sufficient.

It has been years since any phase of motorcar development has so taken the automobile world by storm as have the $\mathrm{V}$ type "Eight" and "Twelve" during the past six months. It must not be inferred that the motors here illustrated are the only ones of V-type now in service. There is at least one more twelve-cylinder car, that of the "National" Motor Car Company, while the "Eights" have grown so numerous that we cannot begin to depict them all. Appearances indicate though, as stated at the beginning, this type will be short-lived if it can be shown that a smaller number of cylinders can accomplish as satisfactory results.

But in thus pointing out the advantage of the eight- and twelve-cylinder motors over the "Four" and "Six," it must be not as yet been in practical use a sufficient length of time for us to obtain data as to its durability and efficiency under all conditions. Faults have been met and overcome, and it will require months of operation in the hands of thousands of users for us to determine accurately what additional faults may arise and whether
they, too, may be overcome or not. In a they, too, may be overcome or not. In a
year from now it will be interesting to note the effect of the V-type motor on tire life, gasoline consumption and, most in portant of all, the driver's "nerves."

\section{How Rifle Bullets Fly}

\section{(Concluded from page if)}

the barrel point at a spot 16 feet higher than the thing we desire to hit, because of the one second we supposed our bullet would take, we have to adjust our sights to make the barrel point at a spot about 30 feet higher than the mark, because, with the constant slowing down of the bullet from the air, it takes 1.6 seconds to make the trip. Thus, the effect of the air in the first place is to make the flight of the bullet a very curved flight, and because of this high curve it has to describe to overcome the influence of gravity during this 1.6 seconds, it would completely miss a man half way out to the mark, even if the rifle were aimed dead at him, with the sights set for 900 yards or 2,700 feet.

Naturally enough, the faster the bullet starts from the muzzle of the rifle, and the better shaped it is to overcome the resistance of the air, the less time it requires to get over a given range. The less time it requires, the less it falls under the pull of gravity and the less it has to rise in its flight. And, rising but little, it is more likely to hit men along the line of its flight even though the sights are not set for the right distance, and the bullet be sent out for a range much farther on. In one case its path is that of the very swiftly thrown baseball, in the other its path is the half-brick slowly describing a parabola through the air. The baseball would not miss anything along the line of its flight by rising over it, the half-brick would not hit anything until it had fallen back toward earth.

This flat flight, termed a "flat trajec tory," in military and ballistic parlance, is the most sought-for attribute of a military rifle. It means that if the range is misjudged, or if the soldiers forget to set their sights correctly, the chance for hitting the enemy is far greater. As judging a range, particularly if the enemy or our own men are on the move, is very difficult the flat trajectory is most important.

Where one bullet, like that from the old black powder Springfield, might rise 10 feet in its flight, a modern bullet will rise stations have been arranged along these lines, thus allowing assistance to be quickwould hit a man anywhere in its path; ly rendered in cases of emergency. At the the old bullet would miss him save where to it. The modern bullet travels at terore than 1,200 feet per second.

Another consideration in being able to a certain spot with a considerable amount of its speed left is the fact that a power. The United States 150-grain sharp-point bullet gets out to 900 yards with 1,140 foot-seconds left. It has the
blow of 433 foot-pounds in energy. If it rgy of 433 foot-pounds and 2,430 footpounds has been taken from the bullet by
its work of overcoming the resistance of mile. So, just as the designer of a yacht studies every line and curve to aid in et designer pares off the point of the ullet and gives it a lean entry to help high speed. had blunt bows, almost canal-boat shape through the air as boats so shaped are adapted to slipping through the water. Since 1905 most of the civilized nation
have adopted the sharp-pointed bullet, socalled spitzer. So efficient has this bee in overcoming air resistance that the buldesigners were enabled to reduce the rains to 150 , without in the least taking overcome the resistance of the air. With the bullet so lightened, they were furthe enabled to drive it at the rate of 2,700 second, without adding to the recoil per rifle, and they thus cut down the weight some 70 grains, or one pound for each 100 So important is the small matter of th arp point on the bullet that adding it mounted to 70 grains out of the 220
grains in ability to drive through the air. If the present 150-grain American bullet the Krag-Jorgensen and on the bullet
the rom the Russian army rifle of to-day eed, it would require 2 seconds to mak trip over 2,700 feet instead of 1.6 secfeet per second speed left instead of 1,140 feet per second, it would have the punch feet above the line of sight instead of 10.5 feet. And all of this is chargeable merely cutting off the sharp point and making the blunt point formerly used, an ing bullets.

But the Americans and the German through the air, and the Swiss have don this with their neighbors, the French Both the Swiss and the French service ng and tapering, and the sterns, instead being cut off square like the Unite tates bullet, taper back precisely like the stern of a racing yacht, to a diameter let. By this means the back-drag of th
locids ir, the vacuum that forms from the hig eed of the bullet, is cut down and so is its speed. There is startlingly little re semblance between the long, graceful, sharp-bowed and taper-stern French and Swiss bullets and the huge, stubby, bluntears ago.

The German Post Office and the German Army

\section{German Army} the old bullet travely 3,000 feet per second got theré with all its 2,700 foot-seconds pounds. The difference between the
poutthe air in traveling little more than a half

Up to 1905 , bullets for military rifles of the cartridge the soldier had to carr only 270 foot-pounds instead of 433 dhe British have failed to go the log-

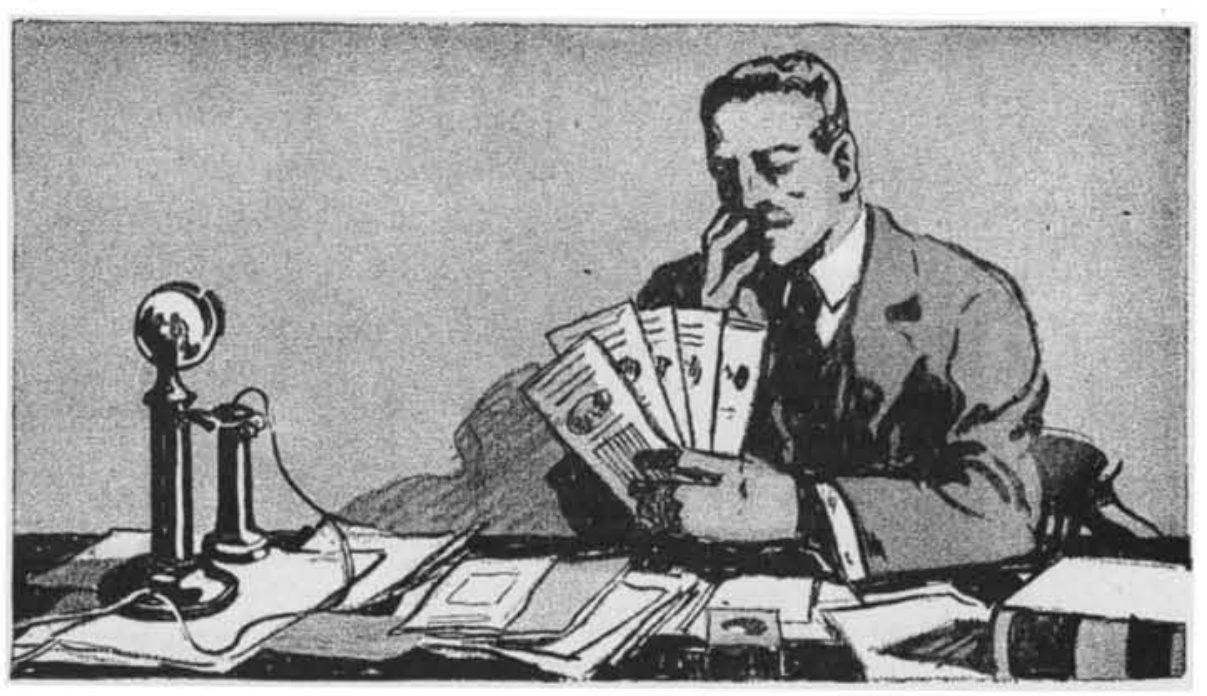

Why Are My Fire Insurance Premiums So Much Higher Than These Six Concerns?

\author{
BY R. S. CHILDS
}

Paid Its Cost 12 Times in 8 Years How the Grinnell System Works

THE following experience of the Peerles Totor Car Company of Cleveland

"Our records show that our Grinnell Automatic Sprinkler equipment has paid for itself insurance premiums."

\$1.11 Rate Reduced to 6 Cents The experience of the Link Belt Company,

Chicago.
"Have been equipped with Grinnell Sprink-
lers 6 years. During that time, loss by fire lers 6 years. During that time, loss by fire
has beenonly $\$ 200$. When we installed Grinnel
System, our rate was reduced from $\$ 1.11$ System, our rate was reduced from
to \$0.06."
Two Fires Extinguished

A letter from the Stromberg-Carlson Tele-
hone Mfg. Co. of Rochester, reade as follows: "We installed Grinnell Automatic Sprinklers
in 1905 and our immediate experience in the in 1905 and our immediate experience in the way of insurance rate reduction was extremely
interesting. Our insurance rate was $\$ 1.50$.

"As soon as the Sprinkler System was completed, our rate was cut from $\$ 1.50$ to $20 \mathrm{c}$. and
has been cut a number of times since then. “On the $\$ 2,000,000$ worth of insurance which we immediately took out, we saved in
the ensuing year $\$ 26,000 . "$

These letters show the money-making phase
of Grinnell Protection. But there is a far of Grinnell Protection.
more interesting phase.

Prevents Business Interruption Letters received lately from 50 great firms
are in agreement that the worst result of fire is interruption of business - the disaster agains which they cannot secure insurance. "Grin-
nells" absolutely protect them against thi nells"
danger.

"We consider the greatest benefit of Grinnell
Sprinklers the protection of the lives of our Sprinklers the protection of the lives of our
employees. NNext, the prevention of business and Paper Compans the West Virginia Pulp and Paper Company, who pay premiums on
policies totaling $\$ 13,500,000$. The Insurance Department of Deere \& Company, the largest plow makers in the
world, says: "We consider the prevention of large fires

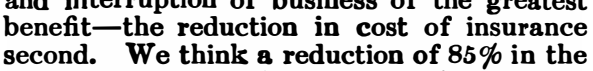
premiums paid is a fair estimate." The opinion of the American Radiator
Company: "We have considered the greates benefit from a Grinnell System to be the in-
creased assurance that our business will not be creased assurance that our business will not be
interrupted through loss by fire. The percentage of reduction in insurance premiums
would estimate at an average of $90 \%$."
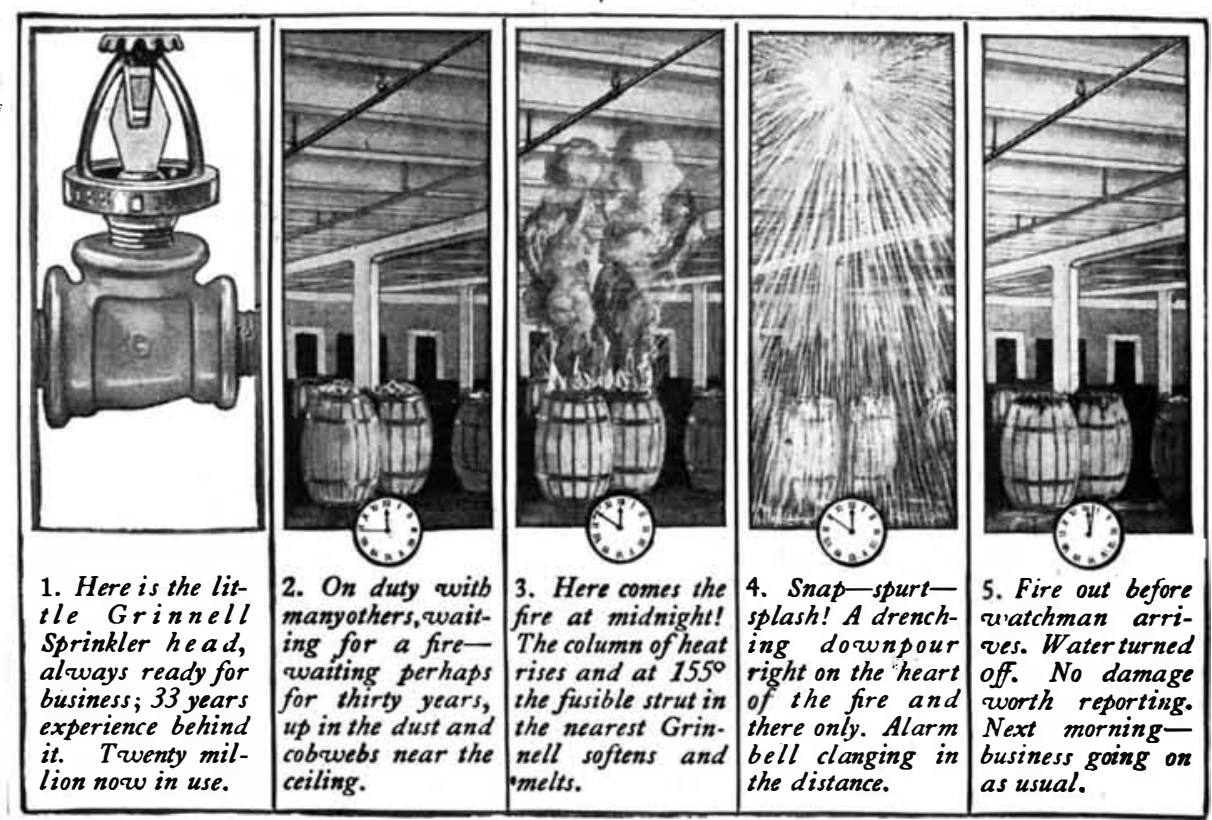

๑ 1915 SCIENTIFIC AMERICAN, INC pipe, smoulders, smokes and silently ignitess.
The little blaze touches dry wood and presently there is a merry little bonfire. The watchman overhead the Grinnell System stands guard.
orta The ascending column of heat spreads and climbs rapidly to $155^{\circ}$; there is $\mathrm{s}$ anap up there and spurt of water and a drenching spray rains down over a space ten feet square while the aovement of water in the pipe rings the distant
realarmand brings the watchman on the run. When he arrives the fire is probably nothing

Grinnell System Preferred The Grinnell System is preferred the world
over by men who want to be safeguarded ver by men who want to be safeguarded
gainst business interruption and demoralization. Some firms have put into their buildings Thinnell equipment costing $\$ 100,000$ or more. Automatic Sprinkler installation, but in Grins disruption by fire. As big buyers of busi-
ness equipment they gained the knowledgeFirst, that metallurgists, engineers, and fire protection experts all grant the superior
fighting qualities of a Grinnell System. Second, that individual Grinnell Systems have proven their infallibility by putting out
as many as 102 different fires in one building. Third, that Grinnell Systems have a thirtythree year record of putting out fires with an
average loss per fire of only $\$ 265$

Let the System Finance Itself And the astounding fact about it all is that as well as large are securing GrinnellSystems or final.

Numerous construction companies will install the system free on the simple basis of
meeting deferred payments with your premim savings each year.

Without obligating yourself in the least, you imply to write the General Fire Extinguisher ngs (including basement and attic), insurance carried on building and rate, together with result in any annoying solicitation, and is Imost sure to show you a way to an annual surance cost.
In the dead of night, let us suppose, a frag-
ment of oily waste kicked under a hot steam R. I., stating the total floor area of your buildinsurance carried on stock, and rate. Your 


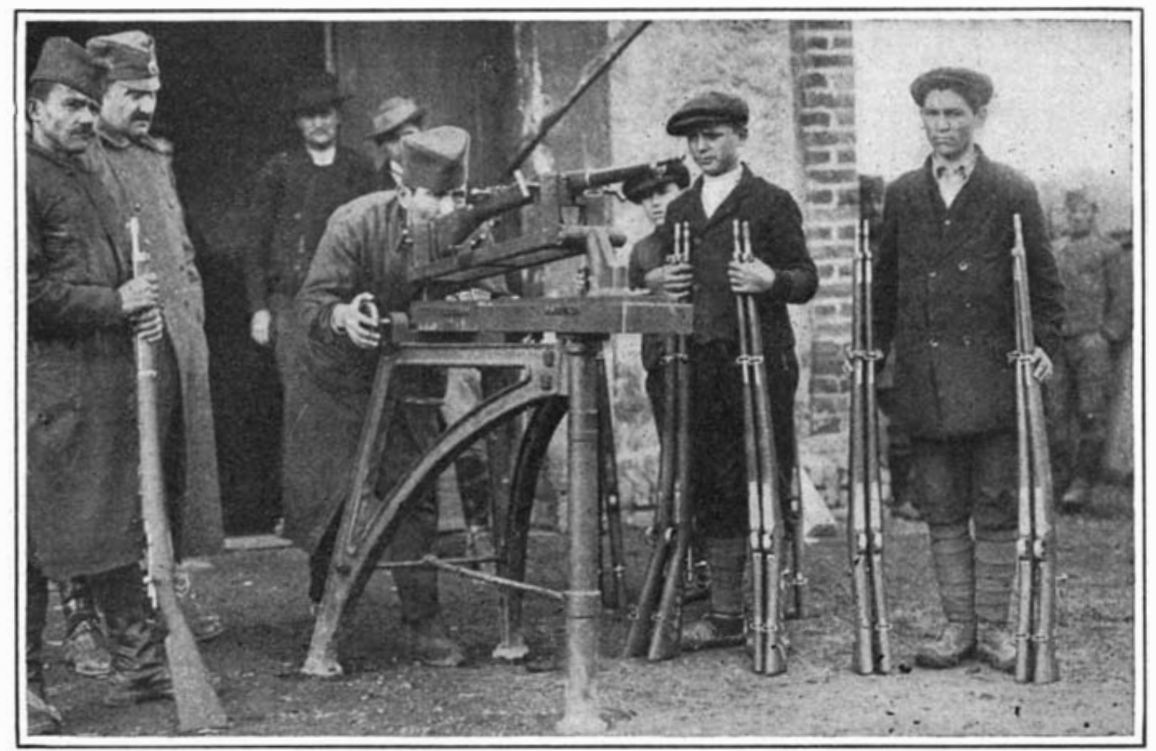

Resighting captured Austrian rifles in Serbia.

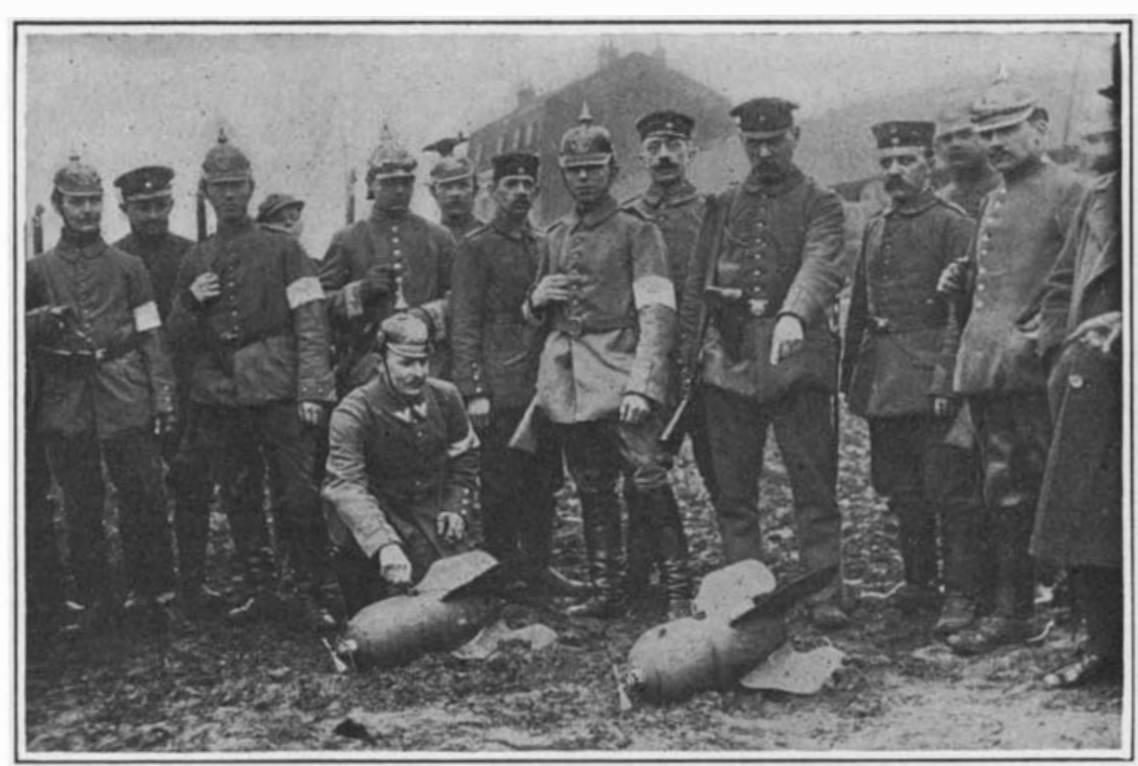

Germans examining the bombs of a captured British aeroplane.

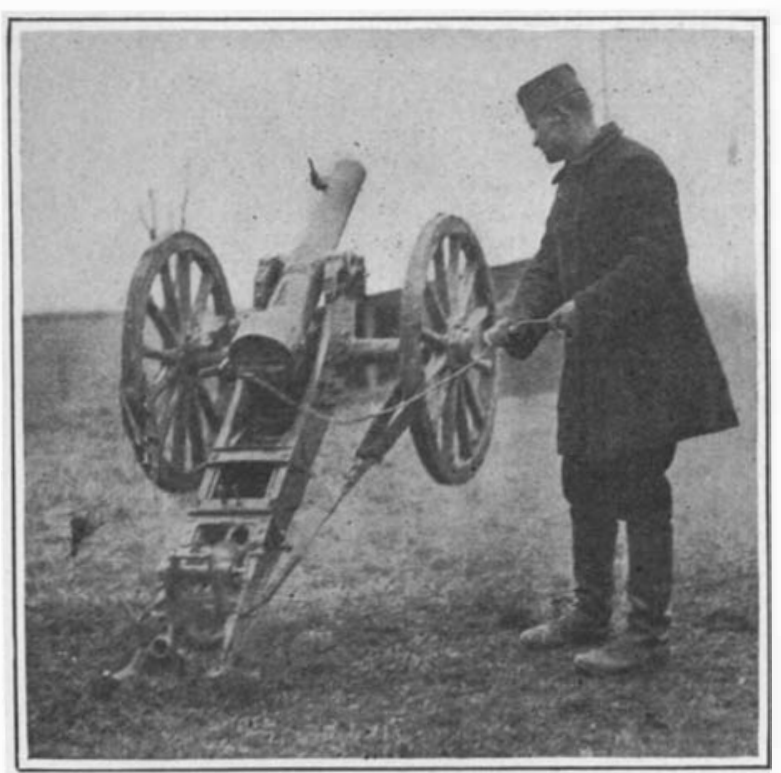

Copyright by International Newe Service

Thrown into the air by the recoil.

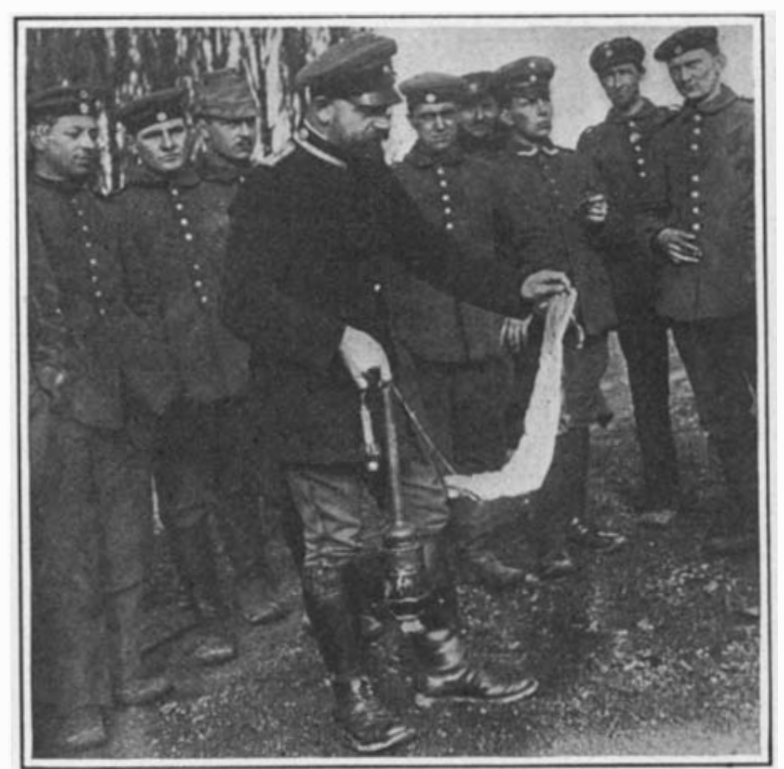

Examining an unexploded French bomb.

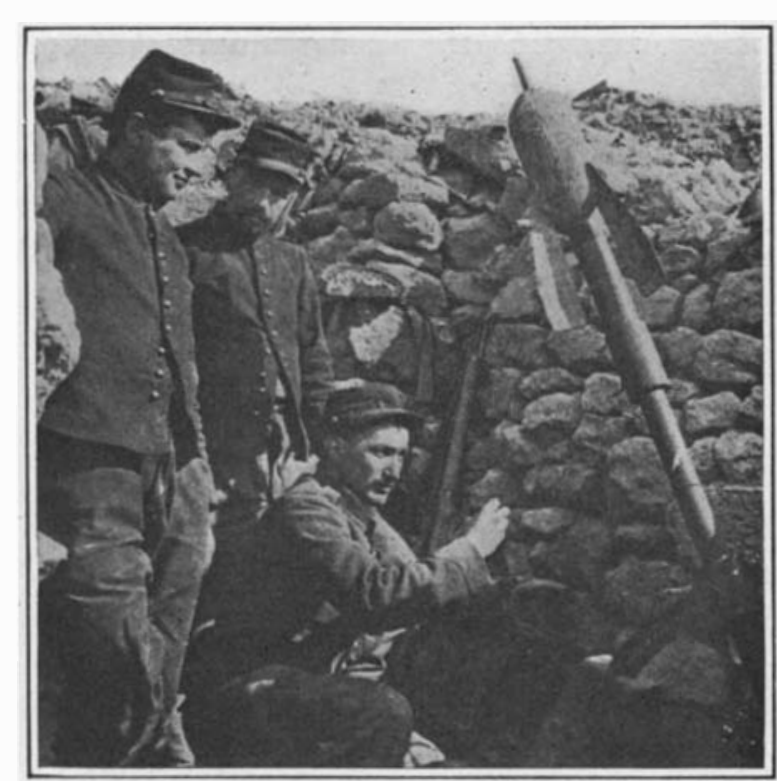

New French "lance-bomb."

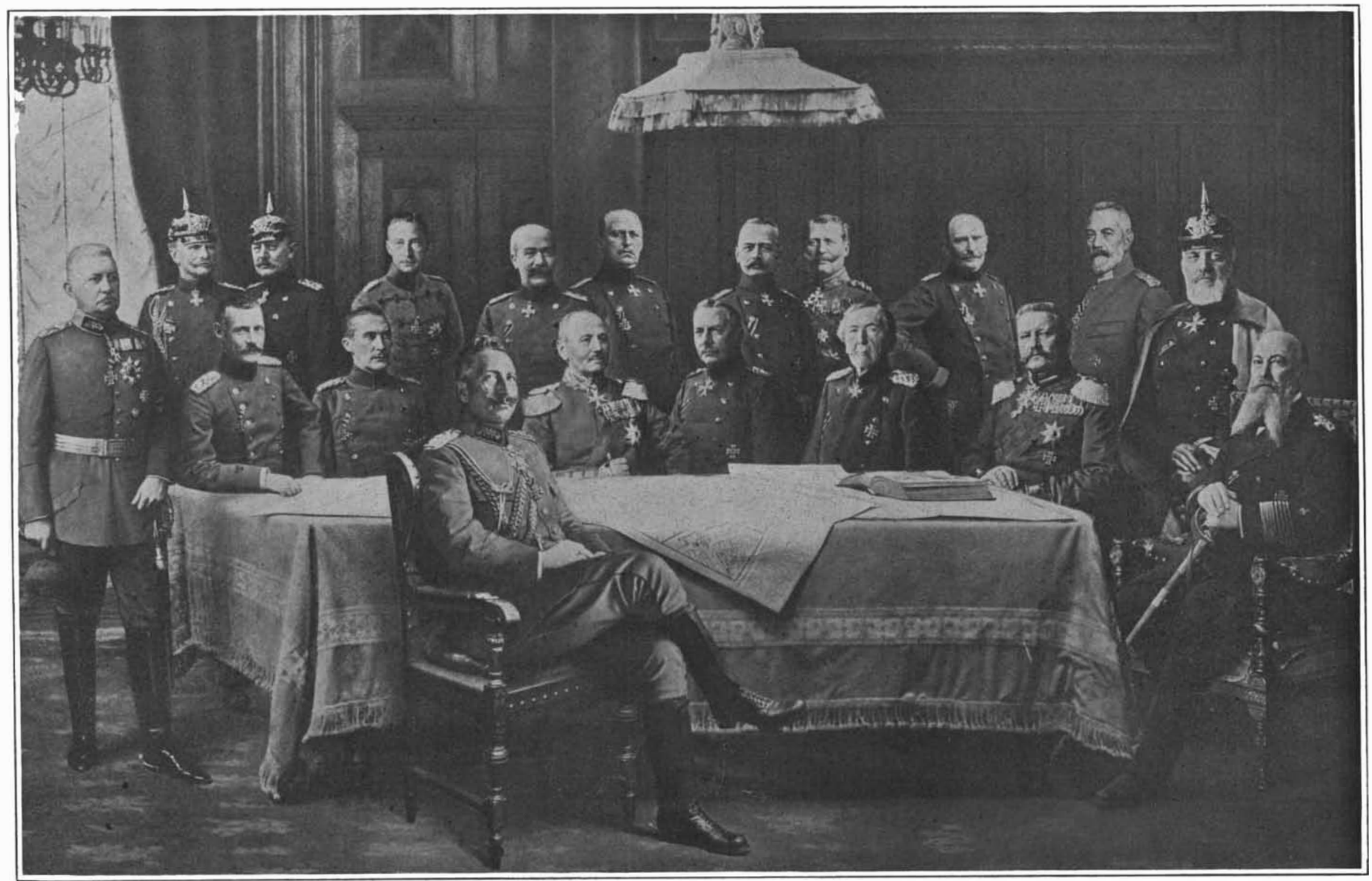

The Kaiser and his military staff.

The Kaiser, in center. Left to right: Seated-Crown Prince Ruprecht von Bayern, Duke Albrecht von Würtemberg, Colonel General von Kluck, General von Emmich, General Field Marshal Count von Haesler, General Field Marshal von Hindenburg, Grand Admiral von Tirpitz. Standing-General Field Marshal von Bülow, General von Mackensen, Chief of General Staff von Moltke, Crown Prince Friedrich Wilhelm, Infantry General von Francois, Chief of General Staff von Ludendorff, Chief of General Staff von 


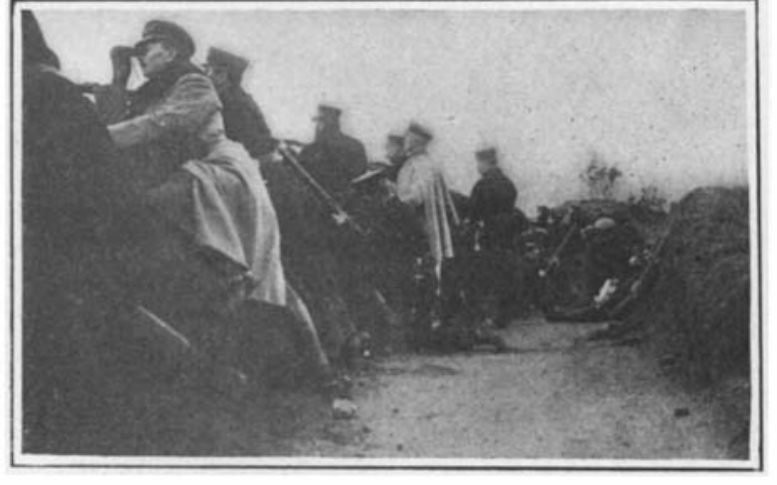

German army officers taking observations:

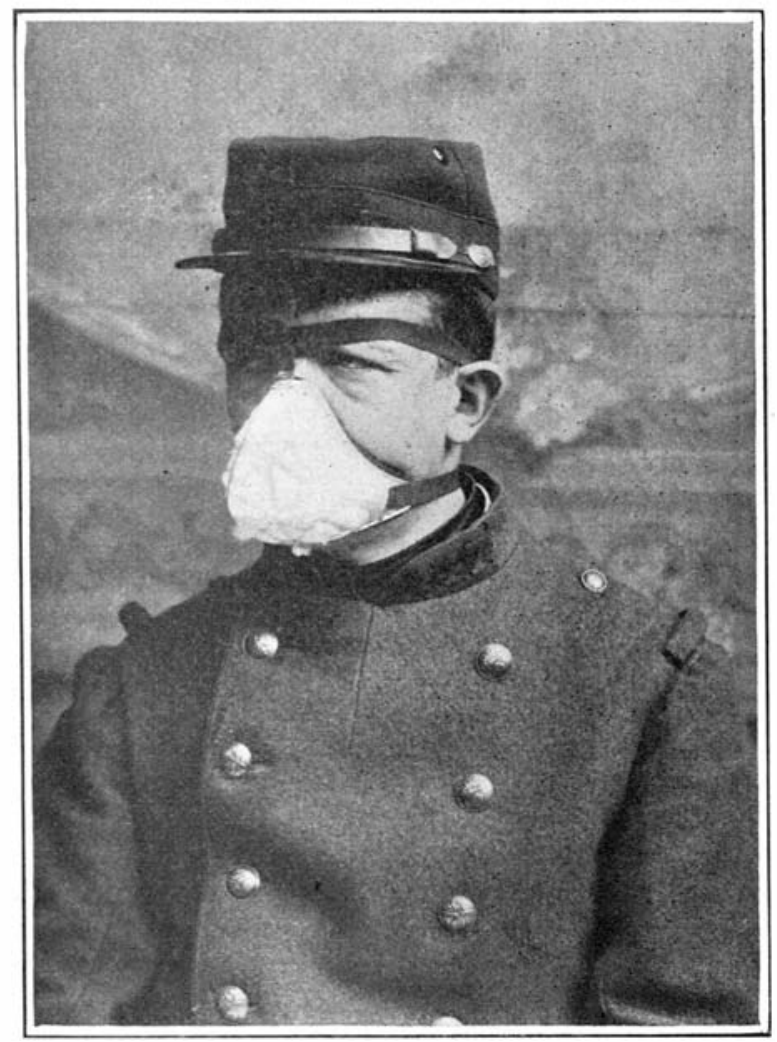

French soldier protected against poisonous gas.

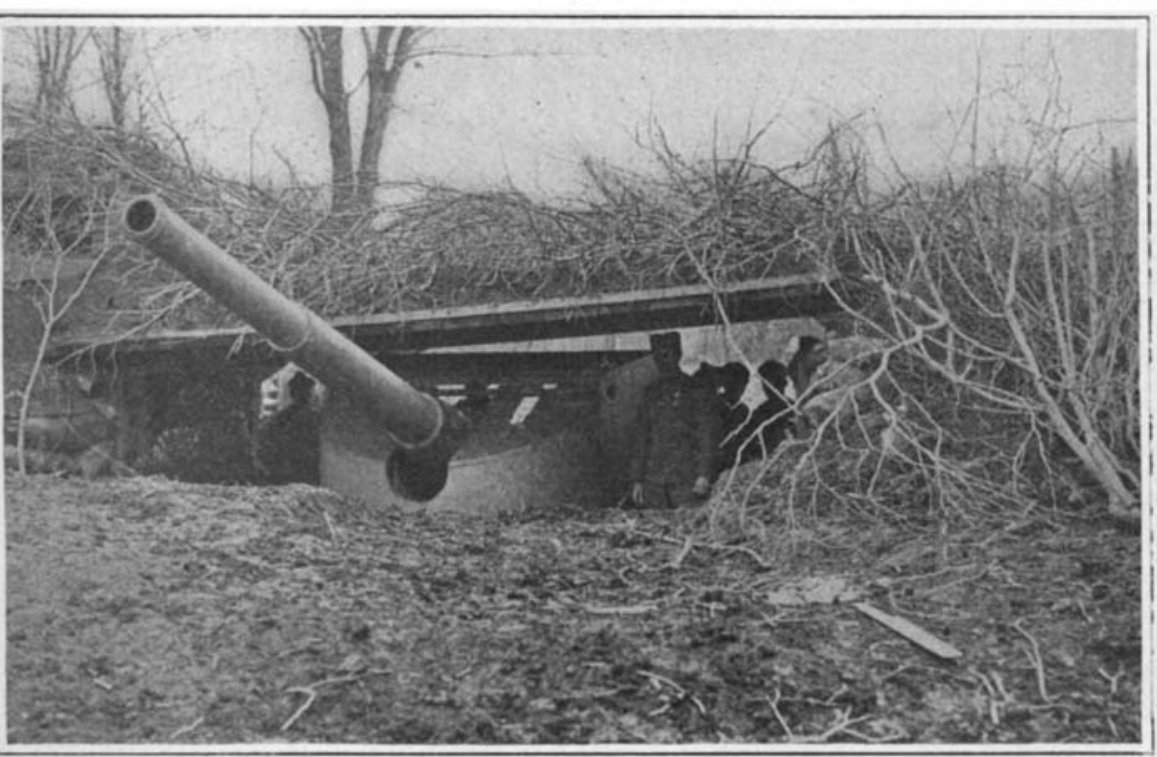

British naval gun doing service in Serbia.

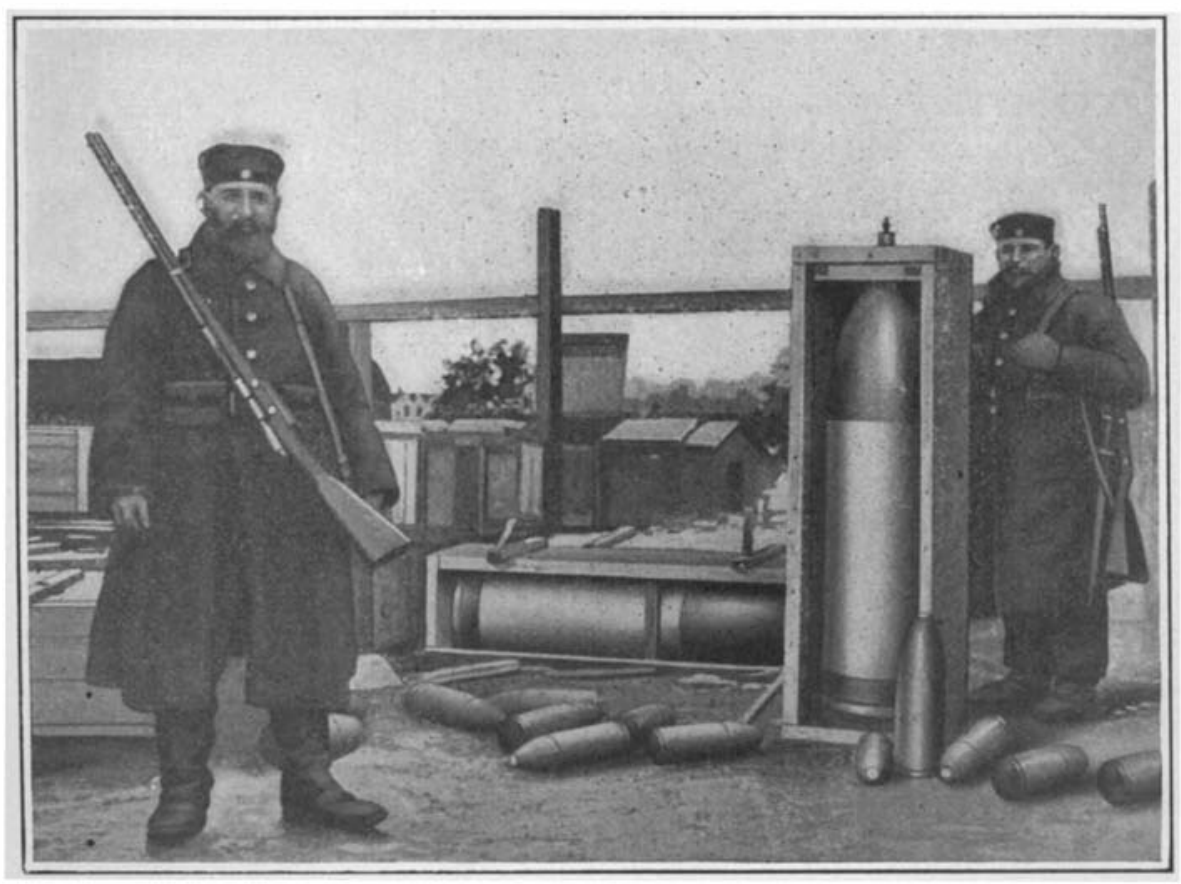

Shells left behind by the Russians in East Prussia.

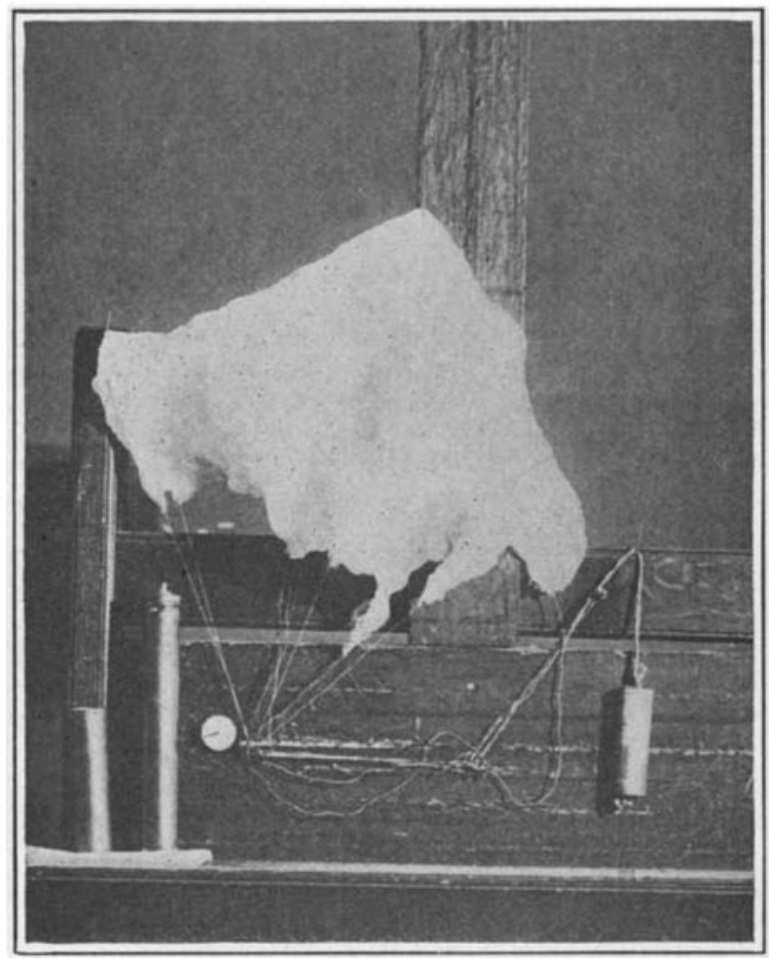

Parachute candles used by Zeppelins in night attacks.

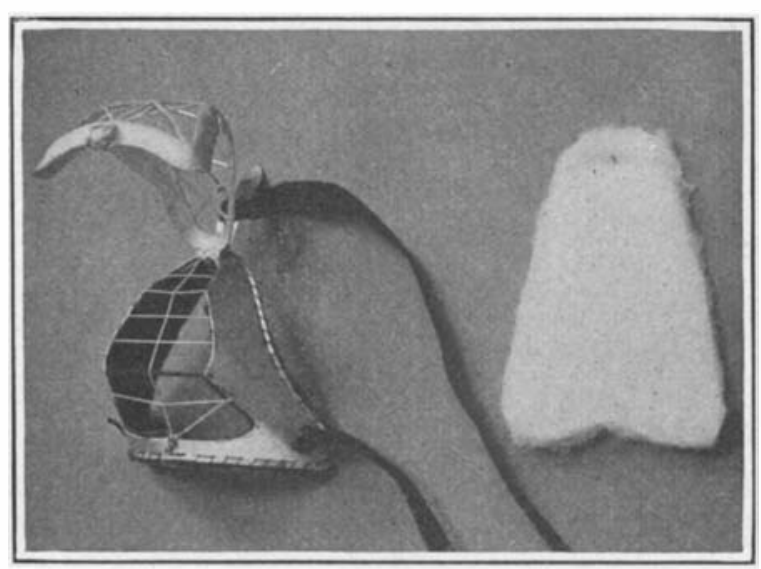

Constructional details of the gas mask.

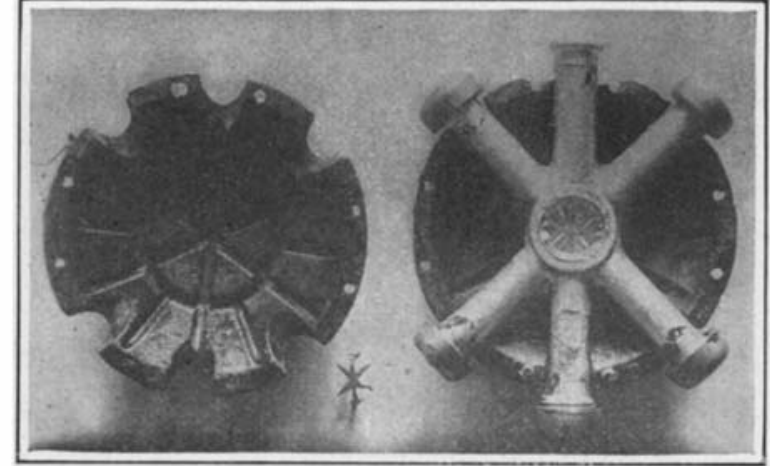

German bomb with radiating cartridges.

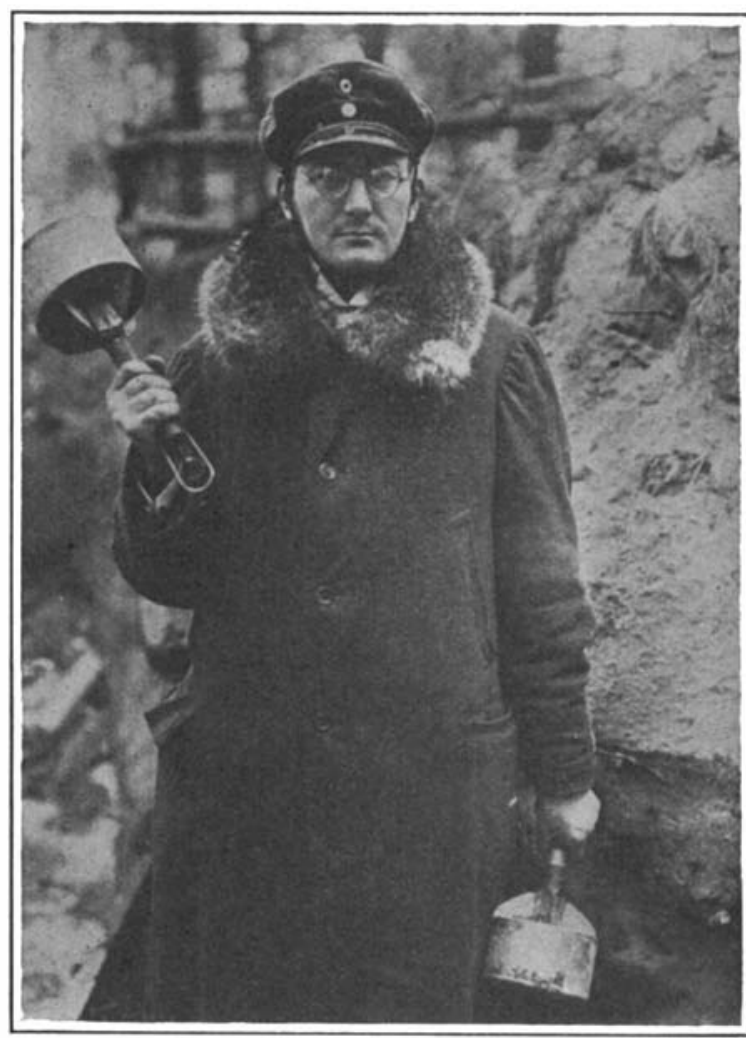

Hand grenades captured in eastern Prussia.

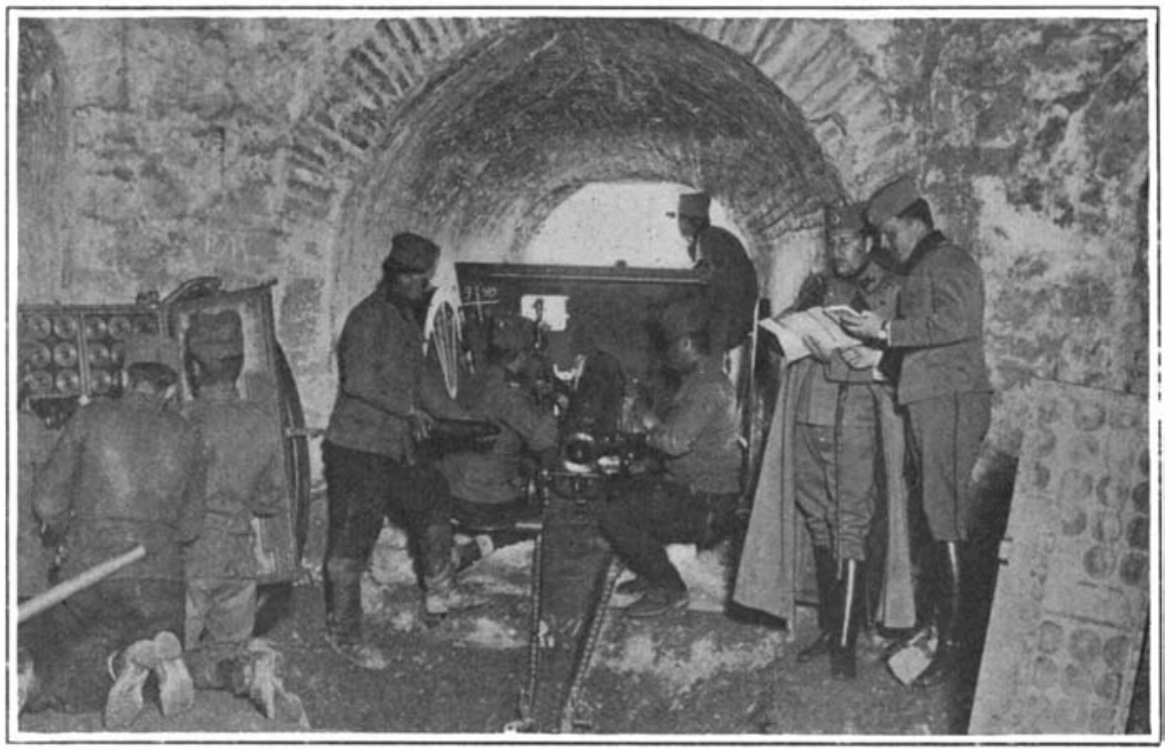

Copyright by Intornastional Newa Sorvlee

A well-concealed gun in Serbia.

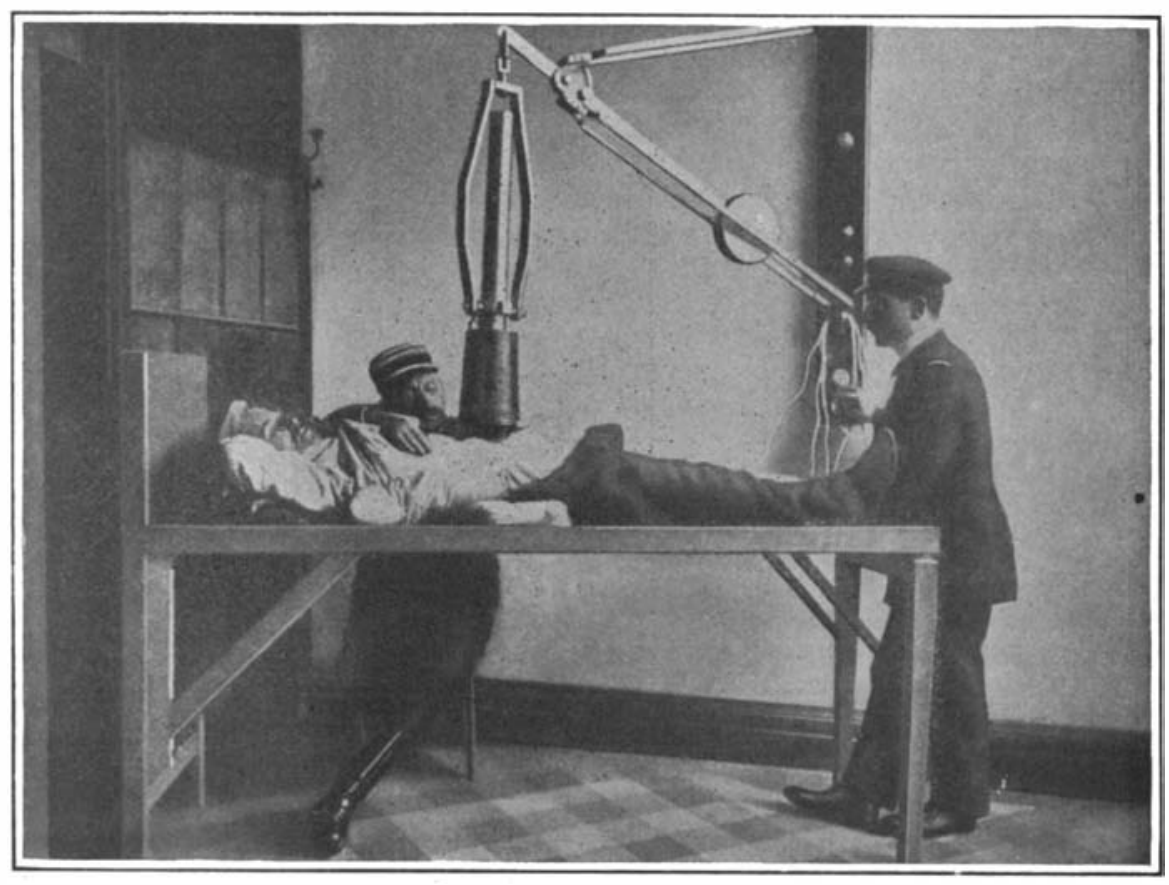

Courtery of Mlusrated London Neves.

Extracting a shell splinter with an electromagnet 